\title{
Modified Importance - Performance Analysis of Airport Facilities- A Case Study of Cochin International Airport Limited
}

\author{
IGY GEORGE \\ Department of Economics, Mar Athanasius College, India
}

\begin{abstract}
This study aims to measure passengers' perception of the importance of the four factors of check-in facility, amenities, terminal facilities, and airport accessibility facility with regard to their visit to the airport and their perceived level of performance of the particular facility and the resulting gap. Using purposive sampling method, data was collected from the departing passengers of the Cochin International Airport Limited. A modified importance-performance analysis (IPA) method is developed using exploratory and confirmatory factor analysis methods with the help of structural equations for the purpose of this study. For the analysis, initially an input model was developed by using AMOS-7 graphics. This initial model is refined to reach the final model. An empirical case study of the perceptions of the passengers about the importance and performance of the facilities at the airport is provided in this paper to test the effectiveness and suitability of the modified IPA and gap analysis in the measurement of the level of performance of a facility. Result of the gap analysis shows that except the check-in facilities there is a gap between importance and satisfaction levels of passengers in respect of the facilities and, the airport authorities should give more attention to the facility management at the airport.
\end{abstract}

Key words: gap analysis, service quality, structural equation modeling

\section{Introduction}

An important issue before the airport management in their pursuit for understanding the customers and market strategy formulation is the evaluation of passenger satisfaction levels of airport facilities [1]. The relationship between the perceptions of service quality and the feelings of satisfaction [2] has attracted many researchers in to this field. According to Parasuraman et al (1991), the quality of facilities has direct link to the passengers' perception of the level of excellence of the facilities provided. Service quality indicators focus on how passengers perceive the level of service provided by the airport and on objective measures of service delivery. [3] Service quality is an important area of airport performance which reflects the efforts made by airport to deliver high standard of service in various areas. Passengers' perception of the importance and performance of the airport facilities are usually assessed by conducting a survey among the departing passengers. Delivering high service quality is considered as an efficient way of ensuring that a company's offerings are uniquely positioned in a market filled with lookalike competitive offerings [3]. Airports constitute a major part of the aviation infrastructure and the existence of many interconnected heterogeneous components such as the diversity of facilities, multiplicity of beneficiaries, sub-systems, rules and regulations, procedures and processes and the deployment of human resources with different classes of responsibilities make it a very complex enterprise. Airport infrastructure comprise of runways, taxiways, ramps, terminals and other facilities in direct control of the airport and the ground infrastructure consists of road and rail networks connecting the airport to the metropolitan areas in the region.[4]

Perception of the passengers is a complex concept and its evaluation requires appropriate instruments, a clear understanding of the relevant dimensions of the concept, development of a valid questionnaire items to measure each of the variables and the assignment of appropriate weights for each variable [5].The concept of service quality has three unique features which are heterogeneity of features, inseparability of production and consumption and intangibility features. The feature of intangibility makes it difficult to understand how the customers perceive the service quality. Many researchers have defined service quality as a measure of how well the service level delivered by the airport matches customers' expectation. It is based on the consumers' judgments about an airport's overall excellence or superiority, which is a form of attitude developed from a comparison of expectation with satisfaction. The term performance can be defined as the performance or satisfaction with the facility and importance can be defined as the impact this performance has on the overall experience. Unlike expectations, which are measured prior to the visit, importance is measured after the visit when the visitor is in a better position to make an informed judgment concerning the facilities that were important to their visit. Satisfaction is an emotional state and customers experience varying levels of satisfaction after they experience a service which they compare with expectations. The main aim of this paper is to measure the importance that the passengers had given to various facilities available at the terminals of an airport and the 
satisfaction perceived by them. For assessing the importance and perception, a modified importanceperformance analysis is conducted.

Previous studies have not targeted on the level of performance of the facilities at the Cochin International Airport Limited (CIAL) and this study is a part of the ongoing research on the various aspects of CIAL. In contrast to the previous researches on the service quality of airport terminals, this study covers a wider area of airport facilities ranging from check-in facility to amenities, terminal facilities and the accessibility features.

\section{Literature Review And Theoretical Background}

In the literature many approaches can be found in defining the concept of service quality. Various propositions about the evolution of service quality in a service organization can be seen in the studies by researchers like Parasuraman et al. (1985) who proposed the service quality gap concept.From the managerial point of view, service quality gap identification is a useful approach. Service quality is a sine qua non for the existence of every service or business unit. Innumerable studies are conducted by various authors and researchers in the field of service quality. Many researchers have proposed extensions to the original quality gaps concept in the later studies.Airport Council International (ACI) [6] and International Civil Aviation Organisation (ICAO) identified service quality as a major factor in measuring the airport performance. Park (1999) introduced a methodology for establishing the operational standards of service performance of airport passenger terminals using a perception-response model. [7]

The theory of 'zone of tolerance' is a deciding factor in the evaluation of service quality of a process or facility. Various aspects of the theory and the different ways various authors [8], [9], [10] explained this concept under different labels were examined by Robert Johnston (1995) [11]. Parasuraman and Berry (1991) defined the zone of tolerance with reference to the customers' evaluation of in-process service performances [3]. The zone of tolerance is a range of service performance that a customer considers satisfactory. The concept of zone of tolerance assumes that there are thresholds in performance perceptions and that satisfaction reactions only appear if these thresholds are exceeded. Campos and Nobrega (2009) [12], attempted to evaluate two affirmations of Zeithaml and Bitner (2003) [13]. "The limits of the tolerance are defined with regard to service desired (SD) and adequate or minimum service (SM). SD represents the level of the service provided, that the customer would like to receive while SM reflects the minimum level of service that the customer would tolerate. When the service is rendered, the customer evaluates the level of service received/perceived, through his or her own perceptions. When the service provided exceeded the desired service level, the customer will be delighted within the zone of tolerance because they have received a service in line with their expectations". Service quality is very important factor at the airport which affects the feedback or perception from the passengers towards the service. When an airport provides an attractive facility or a good quality service to its users it will help it to become a competitive international airport. [14]

According to Philip Kotler, satisfaction is the level of person's felt state resulting from comparing a products' perceived performance (or outcome) in relation to the person's expectations. [15] The gap between perceived service and expectation has given rise to the construct of service quality [16], [17], [18] and to the construct of satisfaction [19], [20] and according to Canel \& Fletcher (2001); satisfaction is linked to performance level of the business [21]. Hence customer satisfaction is the key to business success which can be achieved only by understanding what customers' expect and how they perceive the quality of the service delivery. The level of satisfaction of a service or facility is expressed by consumers after consumption and by comparing the perceived service with expected service.

The importance and performance measures give the management a better understanding of customer perceptions to a facility or service. The Importance Performance Analysis (IPA) framework is a business research technique developed by Martilla and James (1977) and it is a method used to evaluate the qualities of a product or service based on assessment of their importance and performance from the perception of the customer[18]. From the IPA, the management will not only know which attributes require immediate attention, but also why they require immediate attention [22]. The IPA technique identifies strengths and weaknesses by comparing the two criteria that passengers use in making a choice. The two criteria used are the relative importance of attributes and the passengers' evaluation of the service in terms of those attributes. Importance in the present context can be distinguished from expectation and can be defined as the informed judgment by each passenger concerning the facilities available at the airport that were important to their visit. Performance is defined as the satisfaction that each passenger perceived on the available facilities. In contrast, the SERVQUAL technique identifies the customer satisfaction of service attributes by comparing customer's expectation and customer's perception.

Once the values of importance and performance are evaluated the next step is to find out the gap between them. The gap is defined as the mean performance minus the mean importance. Gap analysis typically compares gaps with the benchmark of zero. Positive gaps (performance exceeds importance) are considered satisfactory while negative gaps (where performance is lower than importance) indicate management attention 
may be required [23]. According to Bruyere, et al (2002), importance performance analysis has limited utility except for rare situations in which the target population is homogeneous [24]. More oftern users present a diversity of attitudes and demographics[24]. According to Barsky (1995), lower importance ratings are likely to play a lesser role in affecting overall perceptions, while higher importance ratings are likely to play a more critical role in determining customer satisfaction[25]. The objective is to identify which attributes, or combinations of the attributes are more influential in repeat purchase behavior and which have less impact. The information is valuable for the development of marketing strategies in organizations [26].

The Importance Performance Analysis (IPA) method applied in this study differs from the conventional IPA developed by Martilla and James (1977). Instead of the graphical representation of the mean performance and mean importance calculated from the survey data, structural equations are used to evaluate the regression equation for each of the variables. Using this regression equation, values of each of the variables, which are free of personal prejudices, measurement bias and doubt over the appropriate placement of crosshairs, are found out to determine whether performance and importance are high or low for both the importance and perception. This method will overcome the limitation pointed out by Bruyere, et al (2002) [24].Importance-Performance Analysis (IPA) and the related gap analysis are carried out using these estimated values. This method of conducting importance performance analysis gives results free from measurement bias.

In the present study, a modified Importance-Performance Analysis (IPA) and the related analysis of performance minus importance gaps are carried out using the estimated values of each of the four variables obtained using the regression equation. Structural equations were used to evaluate the regression equation for each of the variables selected. Regression equation gives the relationship between the variables perception and importance expressed by the respondents. For example, one unit of increase/decrease in Qi results Xi unit increase/decrease in performance and Yi unit increase/decrease in importance, where Qi is the standardized regression weights of importance and performance. Hence we get the final equations as,

Performance $=\sum$ Qi Xi

Importance $=\sum$ Qi Yi.

\section{Research Questions And Objectives}

International airports are following uniform procedures in respect of the safety and security issues. But in the case of various facilities and the service quality the performance of the individual airports varies and each airport is having the freedom to decide the level of service extended to the customers. This aspect is reflected in the perception of the passengers about the quality of the services or facilities available at the airport. Here a pertinent question arises about the level of service quality of the various services and facilities at the airport. The airport management will be interested in knowing the importance and performance of the airport facilities perceived by the passengers. Naturally three questions will have to be answered in order to satisfy the quest for knowledge about the service quality level. The three questions are about the importance that the passengers give to the airport facilities, the perception level of the passengers about the airport facilities and the gap if any between importance and performance of facilities.

The objective of the study is to find out the perception of passengers on the importance and the performance of airport facilities available at the airport terminal and the resulting gap.

\section{Research Design And Methodology}

When selecting a framework for the collection and analysis of data, it is essential to consider three important criteria: reliability, replication and validity [27]. Reliability is concerned with the question of whether the results of a study are repeatable. A study must be replicable in order that the reliability of a measure or a concept can be determined. Validity refers to obtaining results that accurately reflect the concept being measured and it implies reliability (consistency). In this study a cross sectional case study method is adopted. The objectives of the study require both quantitative and qualitative methods to be applied in the research. Performance and competitiveness is measured using quantitative methods while qualitative methods are required to measure the perception of the passengers. An exploratory case study approach with triangulation of multiple methods and sources of information has been selected for the study. The research design includes a number of different data sources and methods, including documentary analysis, interviews and questionnaires.

The data on the importance and performance of the passengers on the airport facilities at the airport has been collected from primary sources. Hence, data from a sample size of 300 departing passengers who used Cochin International Airport limited on various dates had been collected through personal interview with a specifically designed questionnaire by applying purposive sampling method. Air passengers arrived earlier was selected for the interview because they have sufficient time to answer the questionnaire. In order to satisfy the Scale refinement and validation of the newly designed questionnaire, various tests are applied. The major forms of validity are content validity, construct validity and face validity. The content validity depends upon a theoretical basis for assuming of a test that it is assessing all domains of a certain criterion, while face validity relates to 
whether the test appears to be good measure, judged by the experts in the field. Convergent validity is one of the approaches to the construct validity refers to the degree to which a measure is correlated with other measures that is theoretically predicted with and it is done by using confirmatory factor analysis where each item in the scale is checked with the help of coefficient called bentler-bonett fit index. It is necessary to assess the statistical reliability of the sample data before any further validation analysis or carrying out Confirmatory Factor Analysis. There are four good methods of measuring reliability. Test-retest technique, multiple forms, inter-rater and Split half reliability. In the case of field survey, internal consistency is estimated by using Cronbach alpha. A high value of the Cronbach alpha coefficient suggests that the items that make up the scale hang together and measure the same underlying construct. An alpha value of 0.70 or above is considered as the criterion for demonstrating strong internal consistency, alpha value of 0.60 or above is considered significant. In this study, Cronbach alpha is calculated for all the four variables and values of Cronbach's alpha shows that refined scale is reliable.

The main aim of this study is to measure the importance that the passengers had given to various facilities available at CIAL and the satisfaction perceived by them. For assessing the importance and perception, a modified importance performance analysis is conducted. From the results, the gap between the importance and performance of the facilities available at the domestic and international terminals are ascertained. The four main variables used in the analysis are the processes related to check-in facility, amenities, terminal facilities and airport accessibility. The main variables are bifurcated in to 28 sub-variables each represented by question. Standardised regression coefficients are used to construct regression models for the importance and performance of airport facilities. Using this regression equation, values of each of the variables are found out to determine whether performance and importance are high or low for the selected variables. Importance-Performance Analysis (IPA) and the related gap analysis are carried out using these estimated values. Exploratory Factor Analysis (EFA) is applied to find the suitability of the four variables and their total considered for the confirmatory factor analysis (CFA) and to identify how far the sub variables (questions) coming under each of the 4 main variables measures them correctly. The EFA model fit indices for the four variables and their totals show that the Kaiser-Meyer-Oklin value exceeding the recommend value of 0.5 and the Bartlett's Test of Sphericity reached statistical significance, supporting the factorability of the correlation matrix. EFA is a method used for testing effects of each of these four main variables and this is done by using a communality of each of the four variables. Communality is the extent to which an item correlates with all other items or in other words, communality gives the variance accounted for a particular variable by all the factors. Higher communalities are better. If the communalities for a particular variable are low (between 0.0-0.4), then, that variable will struggle to load significantly on any factor. Low values indicate questions for removal after examining the pattern matrix. All the communalities calculated in the present study are greater than 0.4 indicating the suitability of factorization with these variables.

Both EFA and CFA are used to understand shared variance of measured variables that can be attributable to a factor or latent construct. EFA and CFA are conceptually and statistically distinct analyses. EFA is used to identify factors based on data and to maximize the amount of variance explained. There are no specific hypotheses about how many factors will emerge, and what items or variables these factors will comprise. Even if these hypotheses exist, they are not incorporated into and do not affect the results of the statistical analyses. In short, EFA deals with theory building while CFA deals with theory testing. The CFA process determines whether the hypothesized structure provides a good fit to the data, or in other words, that a relationship between the observed variables and their underlying latent, or unobserved, constructs exist [28]. CFA evaluates a priori hypotheses that have a theoretical basis. CFA require the researcher to hypothesize, in advance, the number of factors and which measures load on to and reflect which factors. Hence, in contrast to exploratory factor analysis, where all loadings are free to vary, CFA allows for the explicit constraint of certain loadings to be zero. Structural equation modeling (SEM) software is typically used for performing confirmatory factor analysis. CFA is normally used as a first step to assess the proposed measurement model in a structural equation model. Majority of the rules of interpretation for assessment of model fit in structural equation modeling apply equally to CFA. The difference between CFA and structural equation modeling is that in CFA, there are no directed arrows between latent factors. That is, while in CFA, factors are not presumed to directly cause one another, Structural equation modeling often specify particular factors and variables to be causal in nature. In the context of SEM, the CFA is often called 'the measurement model', while the relations between the latent variables with directed arrows are called 'the structural model'.

Fitting a model to data involve solving a set of equations. One side, there is the model with its parameters, whose values we wish to estimate and on the other side there are the sample statistics that we know to be good estimates of the corresponding population values. In SEM, usually it is assumed that the sample data follow a multivariate normal distribution, so that the means and covariance matrix contain all the information. The basic model in statistical modeling is Data $=$ Model + Error. Unlike the other statistical methods, which require only one statistical test to determine the significance of the analyses, in CFA, several statistical tests are 
used to determine how well the model fits to the data. A good fit between the model and the data does not mean that the model is "correct", or even that it explains a large proportion of the covariance. A "good model fit" is the indication that the model is plausible. Absolute fit indices determine how well the a priori model fits, or reproduces the data. Absolute fit indices include, but are not limited to, the Chi-Squared test, RMSEA, GFI, AGFI, RMR, and SRMR. The chi-squared test indicates the difference between observed and expected covariance matrices. The root mean square error of approximation (RMSEA) avoids issues of sample size by analyzing the discrepancy between the hypothesized model, with optimally chosen parameter estimates, and the population covariance matrix. The goodness of fit index (GFI) is a measure of fit between the hypothesized model and the observed covariance matrix. The adjusted goodness of fit index (AGFI) corrects the GFI, which is affected by the number of indicators of each latent variable. The comparative fit index (CFI) analyzes the model fit by examining the discrepancy between the data and the hypothesized model, while adjusting for the issues of sample size inherent in the chi-squared test of model fit, and the normed fit index. The normed fit index (NFI) analyzes the discrepancy between the chi-squared value of the hypothesized model and the chi-squared value of the null model. However, this NFI was found to be very susceptible to sample size. The non-normed fit index (NNFI) also known as the Tucker-Lewis index (TLI), as it was built on an index formed by Tucker and Lewis, in 1973 resolves some of the issues of sample size. Considering the above values, a conclusion was reached about the final model of each factor and their relationships. Correlation was then used to explore the relationships among the factors of independent and moderating variables. Multiple regressions were used to explore the relationship between independent and moderating factors. Structural Equation Models with latent variables (SEM) are used to analyse relationships among variables. These models are used extensively in researches due to their parsimony (they belong to the family of linear models), their ability to model complex systems (where simultaneous and reciprocal relationships may be present, such as the relationship between quality and satisfaction), and their ability to model relationships among non-observable variables while taking in to account measurement errors.

\section{Data Analysis And Results}

Survey data show that $36 \%$ of the domestic travelers and $21.3 \%$ percentage of the international travelers are in the age group of 18 to28. The domestic and international passengers in the age group 29-42 are $38 \%$ and $41.3 \%$ respectively. The domestic and international passengers in the age group of $43-55$ are $19.3 \%$ and $6.7 \%$ and in the age group 56-65 are and $33.3 \%$ and $4 \%$ respectively. Also $82 \%$ of the respondents are males and $18 \%$ of the respondents are females.

The perceived performance of the facilities at the airport was evaluated using 28 independent variables (questions) and 4 dependent variables. The values of the variables check-in facility, amenities, terminal facilities and airport accessibility are calculated as the sum of the questions coming under each of these dependent variables. All the communalities calculated are greater than 0.4 indicating the suitability of factorization with these variables. The fit indices, the error measure and the goodness of fit measures for the CFA model given in figure 1 and 2 are exhibited in Table 1. These measures indicate well fit of the model for both the Performance and Importance. For the analysis, initially an input model was developed by using AMOS-7 graphics. This initial model is refined to reach the final model.

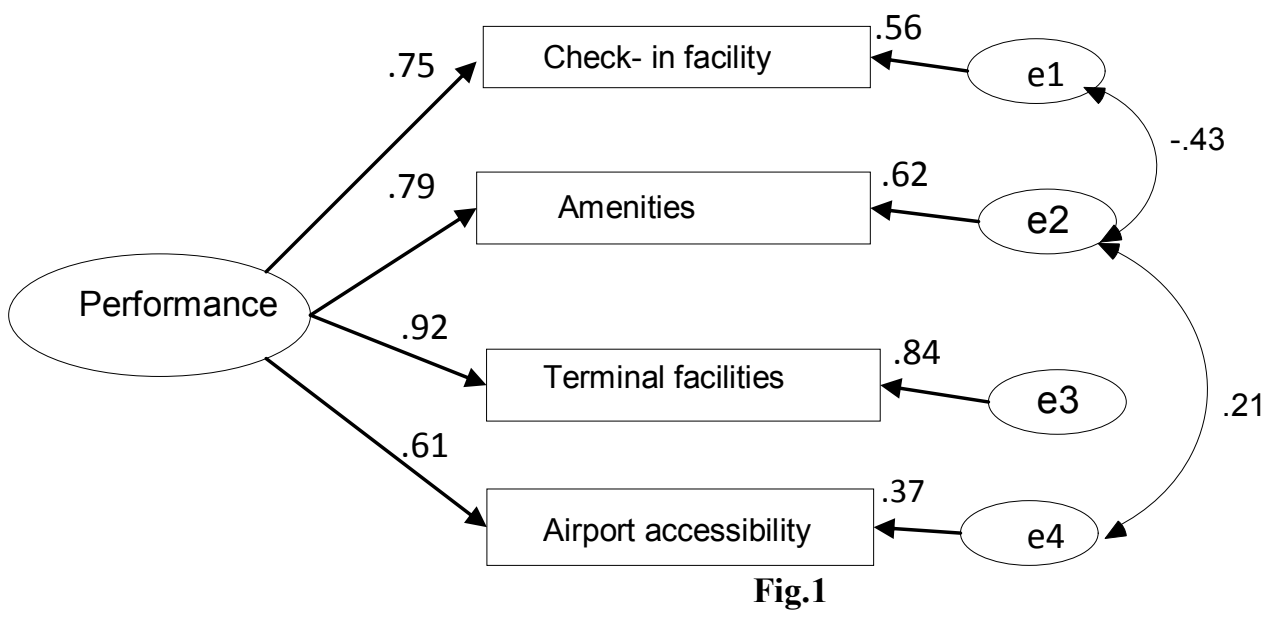

The path diagram given in the figure 1 shows that the contributing factors for the perception of performance of airport facilities in the order of priority are terminal facilities, amenities, check-in facility and airport accessibility and their regression weights/ factor loadings are $0.917,0.786,0.747$ and 0.609 respectively. The squared multiple correlations $\left(\mathrm{R}^{2}\right)$ indicate that terminal facilities, amenities, check in facility and airport 
accessibility with values $0.84,0.62,0.56$ and 0.37 respectively predict the perception of performance of airport facilities.

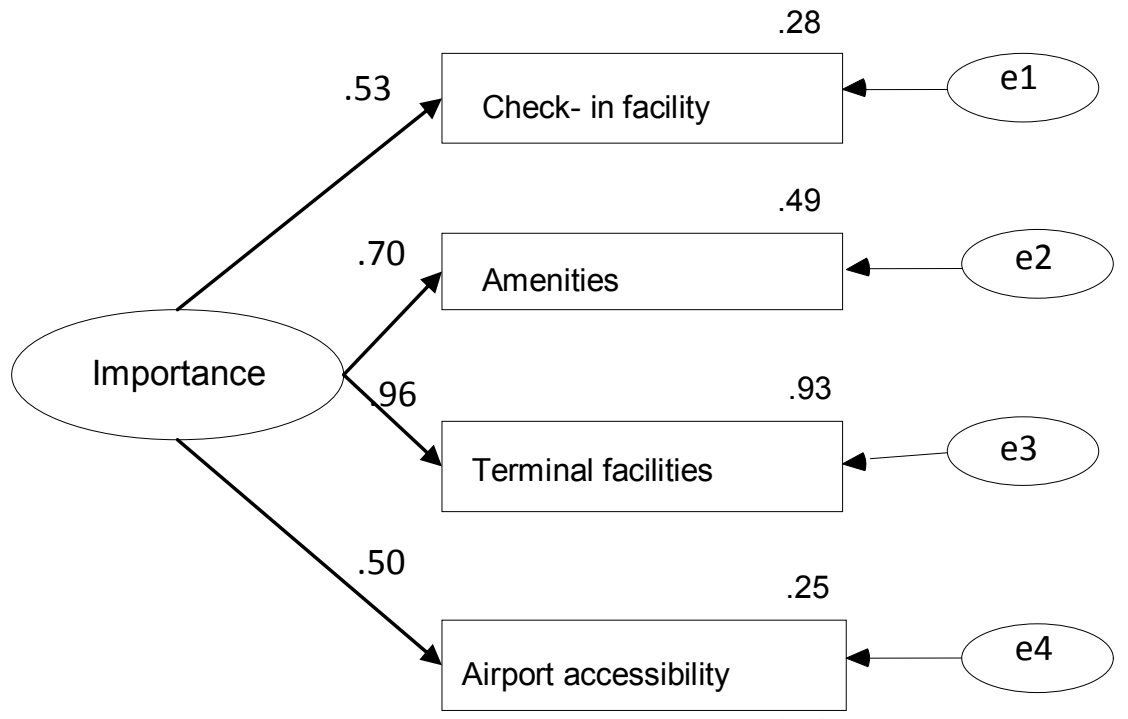

Fig.2

The path diagram given in the figure 2 shows that the contributing factors for the importance of overall service quality in the order of priority is terminal facilities, amenities, Check-in facility and airport accessibility with regression weights/ factor loadings $0.962,0.702,0.530$ and 0.500 respectively. The squared multiple correlations $\left(\mathrm{R}^{2}\right)$ indicate that terminal facilities, amenities, check in facility and airport accessibility with values $0.93,0.49,0.28$ and 0.25 respectively predict the importance of overall service quality of the international terminal. The regression coefficients are given in table 1 and the corresponding regression equations are given in equations 3 and 4 .

Table 1 Standardized Regression Weights

\begin{tabular}{|l|c|c|}
\hline & Performance & Importance \\
\hline Check- in facility & .747 & .530 \\
\hline Amenities & .786 & .702 \\
\hline Terminal facilities & .917 & .962 \\
\hline Airport accessibility & .609 & .500 \\
\hline
\end{tabular}

Source: Research data

The regression model for the performance and importance of airport facilities are

Performance $=0.747$ Check in facility +0.786 Amenities +0.917 Terminal facilities

+0.609 Airport accessibility

Importance $=0.530$ Check in facility +0.702 Amenities +.962 Terminal facilities

+0.500 Airport accessibility

Using these regression equations, the values of performance and importance assessed by each respondent for the four variables and the totals are calculated which are used for the Importance-Performance Analysis. The mean values and the resultant gap and the $\mathrm{p}$-values are calculated for each variable.

Table 2 Mean, Gap and $\mathrm{p}$ values

\begin{tabular}{|l|c|c|c|c|}
\hline \multirow{2}{*}{ Variables } & PERFORMANCE & IMPORTANCE & \multirow{2}{*}{ GAP } & \multirow{2}{*}{ - VALUE } \\
\cline { 2 - 3 } & Mean & Mean & & \\
\hline Check -in facility & 14.08 & 14.37 & -0.28 & 0.398 \\
\hline Amenities & 4.13 & 7.55 & -3.43 & $<0.001$ \\
\hline Terminal facilities & 18.28 & 21.57 & -3.29 & $<0.001$ \\
\hline Airport accessibility & 4.26 & 12.92 & -8.66 & $<0.001$ \\
\hline Overall facilities & 61.10 & 66.92 & -5.82 & $<0.001$ \\
\hline
\end{tabular}

Source: Research data

(*) Significant at $1 \%$ level 
The gap value for check-in facility is 0.28 which is statistically not significant. The gap values for the other variables and the overall facilities as given in Table 1 are statistically significant at $1 \%$ level which shows that the quality of the facilities at the airport needs improvement.

\section{Conclusions And Implications}

The outcome of the study shows that passengers' perception of both the importance and performance of the facilities at the airport are dominated by their experience at the terminal hall followed by the amenities, check-in facility and the accessibility. The result of the gap analysis shows a gap between importance and satisfaction levels of passengers and hence, the airport authorities should give more attention to the facility management at the airport.

\section{References}

[1]. Yeh, C.H. and Kuo, Y.L. (2003), Evaluating Passenger Service of Asia-Pacific Airports, Transportation Research, Part E, 39, pp. $107-115$

[2]. Anderson, John Robert. Rules of the Mind, Psychology Press, Hillsdale, 1993.

[3]. Parasuraman A., Zeithaml, Valerie. (1985). A conceptual model of service quality and its implications for future research. Journal of Marketing, 49, 41-50

[4]. Grancay, M. Evaluating competitiveness of airports - Airport competitiveness index. Munich Personal RePEc Archive (16488), 2009.

[5]. Carme Saurina, G. C. Predicting Overall Service Quality. A Structural Equation Modeling Approach. A. F. (Ed.) Developments in Social Science Methodology, 2002, 217-238.

[6]. Airport Council International, Airport Performance Measurement - Guide to Airport Performance Measures, Oliver Wyman Inc, 2012 .

[7]. Park, Y. (1999). A methodology for establishing operational standards of airport passenger terminals. Journal of Air Transport Management, 5 (2), 73-80.

[8]. Miller, J.A. Exploring Satisfaction, Modifying models, Eliciting Expectation, Posing Problem and Making Meaningful Measurements, in Conceptualization and measurement of consumer satisfaction and Dissatisfaction, Hunk, H.K. (Ed.) Marketing Science Institute, Cambridge. Massachusetts, 1977,

[9]. Oliver, R.L. (1980). A Cognitive model of the Antecedents and Consequences of Satisfaction Decisions, Journal of Marketing Research, Vol.17, 460-469

[10]. Swan, J. E. (1988), Consumer Satisfaction Related to Disconfirmation of Expectation and Product Performance, Journal of Consumer Satisfaction Dissatisfaction and Complaining Behavior, 1, 40-47

[11]. Johnston, Robert. The Zone of Tolerance: Exploring the Relationship between Service Transaction and Satisfaction with the overall Service, International Journal of Service Industry Management, 6 (2), 1995, 46-61

[12]. Campos, D. F., Nobrega, K. C.: Importance and the Zone of Tolerance of Customer Expectations of Fast Food Services Journal of Operations and Supply Chain Management 2 (2), 2009, 56 - 71, C International Conference of the Production and Operations Management Society

[13]. Zeithaml, V.A. and Bitner, M.J., Services Marketing: Integrating Customer Focus Across The Firm, McGraw Hill, New York, 2003. [14]. Norudin Mansor, \&. S. Internationalization of Service Quality: A Case of Kuala Lumpur International Airport, Malaysia. International Journal of Business and Behavioral Sciences, 2 (12), 2012 11-25.

[15]. Kotler, P. Marketing Management: An Asian Perspective. Prentice-Hall, 1998.

[16]. Zeithaml, V. A, Berry, L. L and Parasuraman, A. (1996). The Behavioral Consequences of Service Quality. Journal of Marketing, $60,31-46$.

[17]. Wisniewski, M. and Donnelly, M. (2010). Measuring Service Quality in the Public Sector: The Potential of SERVQUAL. Total Quality Management, 7 (4), 357-365.

[18]. Woodruff, R. B., Cadoltte, E. R. and Jenkins, R.L., (1985), Modeling Consumer Satisfaction Process Using Experiences Based Norms, Journal of Marketing Research, 20, 296-304.

[19]. Kotler, P. and Armstrong G. Principles of Marketing, $10^{\text {th }}$ Edition Chapter 7, 2004.

[20]. Zahorik, A. J and Rust, R.T., Modeling the Impact of Service Quality of Profitability: A Review: in Swartz T.A., Bowen, D.E. and Brown, S.W. (Eds), Advances in services marketing and management, 2007, 49-64. Greenwich, CT: JAI Pressed.)

[21]. Fletcher, C. E. (2001). Hospital registered nurses' job satisfaction and dissatisfaction. Journal of Nursing Administration, 31(6): 324-331.

[22]. Bacon, D.R. A comparison of approaches to importance- performance analysis, International Journal of Market Research, 45, 1(2003), 55-71.

[23]. Taplin, Ross. H. (2012). Competitive importance-performance analysis of an Australian wildlife park. Tourism Management journal, 33 (1), 29-37.

[24]. Brett L. Bruyere, D. A. Enhancing Importance-Performance Analysis through Segmentation. Journal of Travel \& Tourism Marketing, 12 (1), 2002, 81-95.

[25]. Barsky, J. World-Class Customer Satisfaction, Chicago, IL: Irwin Publishing., 1995

[26]. Ford, J. B. Importance - performance analysis as a strategic tool for service marketers: the case of service quality perceptions of business students in New Zealand and the USA. European Journal of Marketing, 27 (2), 1991, 59-70.

[27]. Bryman, A. Social Research Methods. Oxford: Oxford University Press, 2004.

[28]. Child, Dennis. The Essential of Factor Analysis. $3^{\text {rd }}$ Edition. Cassel Educational Ltd. London, 1990 